\title{
Shape Memory Behavior of Ti-22Nb-(0.5-2.0)O(at\%) Biomedical Alloys
}

\author{
Jae Il Kim ${ }^{1}$, Hee Young Kim ${ }^{1}$, Hideki Hosoda ${ }^{2}$ and Shuichi Miyazaki ${ }^{1, *}$ \\ ${ }^{1}$ Institute of Materials Science, University of Tsukuba, Tsukuba 305-8573, Japan \\ ${ }^{2}$ Precision and Intelligence Laboratory, Tokyo Institute of Technology, Yokohama 226-8503, Japan
}

In order to develop new biomedical shape memory alloys, mechanical properties and shape memory behavior of $\mathrm{Ti}-22 \mathrm{Nb}-(0.5-$ $2.0) \mathrm{O}(\mathrm{at} \%)$ alloys were investigated by tensile tests at various temperatures and $\mathrm{X}$-ray diffraction measurement. The Ti- $\mathrm{Nb}-\mathrm{O}$ alloys were fabricated by an arc melting method and then homogenized at $1273 \mathrm{~K}$ for $7.2 \mathrm{ks}$. The ingots were cold-rolled with a reduction up to $98.5 \%$ in thickness and solution treated at $1173 \mathrm{~K}$ for $1.8 \mathrm{ks}$. The fracture stress of both as-rolled specimen and solution treated specimen increased with increasing oxygen content. A fracture stress of $1.37 \mathrm{GPa}$ was obtained in the as-rolled $\mathrm{Ti}-22 \mathrm{Nb}-2 \mathrm{O}$ alloy. The martensitic transformation temperature decreased by $160 \mathrm{~K}$ per 1 at $\%$ increase of oxygen content. Superior shape memory effect and superelastic behavior were observed at room temperature in the $\mathrm{Ti}-22 \mathrm{Nb}-(0.5-1.5) \mathrm{O}$ alloys. The addition of oxygen stabilized superelastic behavior of Ti-Nb alloys by increasing the critical stress for permanent deformation. The maximum shape recovery strain of $4.0 \%$ and the critical stress of $900 \mathrm{MPa}$ for permanent deformation were obtained in the $\mathrm{Ti}-22 \mathrm{Nb}-0.5 \mathrm{O}$ and $\mathrm{Ti}-22 \mathrm{Nb}-1.5 \mathrm{O}$ alloys, respectively.

(Received January 11, 2005; Accepted February 16, 2005; Published April 15, 2005)

Keywords: shape memory alloy, superelasticity, biomaterials, smart material, titanium based alloy, titanium-niobium-oxygen, interstitial element

\section{Introduction}

Biomedical shape memory alloys are required to have superior corrosion resistance, biocompatibility, excellent shape memory property and absolute safety to human body. Among many shape memory alloys, only $\mathrm{Ti}-\mathrm{Ni}$ shape memory alloys have been widely applied for biomedical uses to date. However, although Ni-hypersensitivity to human body in $\mathrm{Ti}-\mathrm{Ni}$ alloys has not been reported, Nihypersensitivity has been pointed out in pure Ni. ${ }^{1)}$ Therefore, it is preferable to develop absolutely safe Ni-free Ti-based shape memory alloys for biomedical applications.

Many $\beta$-type Ti-based alloys exhibiting shape memory effect have been studied by many researchers, e.g., Ti-V based alloys, ${ }^{2)}$ Ti-Mo based alloys ${ }^{3-9)}$ and $\mathrm{Ti}-\mathrm{Nb}$ based alloys. ${ }^{10-18)}$ It is confirmed that mechanical properties can be improved by addition of the third or more elements to these binary based alloys. Ti-based ternary alloys have been studied for developing biomedical shape memory alloys as follows; (i) Ti-Mo-Ge, ${ }^{5)} \mathrm{Ti}-\mathrm{Mo}-\mathrm{Ga},{ }^{8)} \mathrm{Ti}-\mathrm{Mo}-\mathrm{Sn},{ }^{6)} \mathrm{Ti}-\mathrm{Nb}-$ $\mathrm{Sn}^{11)}$ and $\mathrm{Ti}-\mathrm{Nb}-\mathrm{Al}^{12)}$ which include an $\alpha$-stabilizer for the third element, (ii) $\mathrm{Ti}-\mathrm{Nb}-\mathrm{Ta}^{17)} \mathrm{Ti}-\mathrm{Nb}-\mathrm{Mo}^{18)}$ and $\mathrm{Ti}-\mathrm{Mo}-$ $\mathrm{Ta}^{9)}$ which include a $\beta$-stabilizer for the third element, (iii) $\mathrm{Ti}-\mathrm{Nb}-\mathrm{Au},{ }^{15)} \mathrm{Ti}-\mathrm{Nb}-\mathrm{Pt},{ }^{16)} \mathrm{Ti}-\mathrm{Nb}-\mathrm{Pd}^{19)}$ and $\mathrm{Ti}-\mathrm{Mo}-\mathrm{Ag}^{6}{ }^{6}$ which include a noble metal for the third element, and (iv) $\mathrm{Ti}-\mathrm{Nb}-\mathrm{Zr}^{14)}$ and $\mathrm{Ti}-\mathrm{Nb}-\mathrm{Sc} .^{7)}$ It has been reported that these ternary alloys exhibit considerably stable shape memory and superelastic behavior. Other attractive candidates for the third element to the $\beta$-type Ti-based binary shape memory alloys are interstitial elements which are also $\alpha$-stabilizers, such as oxygen, carbon and nitrogen. To date, although the effect of addition of these interstitial elements, nitrogen or oxygen, on shape memory behavior has been investigated, ${ }^{20,21)}$ it has not been systemically reported in the literature.

Recently, unique Ti-based alloys called 'GUM METAL' with a low Young's modulus have been developed. ${ }^{22)}$ These alloys exhibit properties such as low elastic modulus, high strength and large elastic strain. These characteristics originate from the addition of oxygen to $\beta$-type biomedical alloys, such as Ti-12Ta-9Nb-3V-6Zr or Ti-23Nb-0.7Ta$2 \mathrm{Zr}(\mathrm{mol} \%)$. The addition of oxygen caused the strength of the alloys to increase, resulting in large elasticity of more than $2 \%$. This suggests that addition of oxygen is also effective to develop stable shape memory and superelastic behavior in the $\beta$-type shape memory alloys.

In this study, in order to develop Ni-free Ti-based biomedical shape memory alloys, we investigated the effect of adding oxygen to the binary $\mathrm{Ti}-\mathrm{Nb}$ alloy on mechanical properties and shape memory behavior by tensile tests at various temperatures and XRD measurement.

\section{Experimental Procedures}

Ti-22 at $\% \mathrm{Nb}-(0.5-2.0)$ at $\% \mathrm{O}$ ingots were made by the Arc melting method using pure titanium, pure niobium and $\mathrm{TiO}_{2}$, followed by homogenizing at $1273 \mathrm{~K}$ for $7.2 \mathrm{ks}$. The ingots were cold-rolled to plates of about $0.13 \mathrm{~mm}$ in thickness. Final cold working ratio was $98.5 \%$ in thickness. The specimens for the XRD (X-ray diffraction) measurement and tensile tests were cut from the plates by an electro-discharge machine. All specimens were finally solution-treated at $1173 \mathrm{~K}$ for $1.8 \mathrm{ks}$ or annealed at $773-1073 \mathrm{~K}$ for $3.6 \mathrm{ks}$ in $\mathrm{Ar}$ atmosphere, followed by quenching into water at room temperature. In order to remove lightly oxidized surface, the specimens were etched after the heat-treatment. In order to investigate their shape memory characteristics, tensile tests were carried out at various temperatures. The gage length and width of the specimens for tensile tests were $20 \mathrm{~mm}$ and $1.5 \mathrm{~mm}$, respectively. XRD measurement was conducted at room temperature with $\mathrm{Cu} \mathrm{K} \alpha$ radiation to determine the constituent phases. The dimension of the samples for XRD measurement was of $8 \times 7 \times 0.12 \mathrm{~mm}^{3}$. 

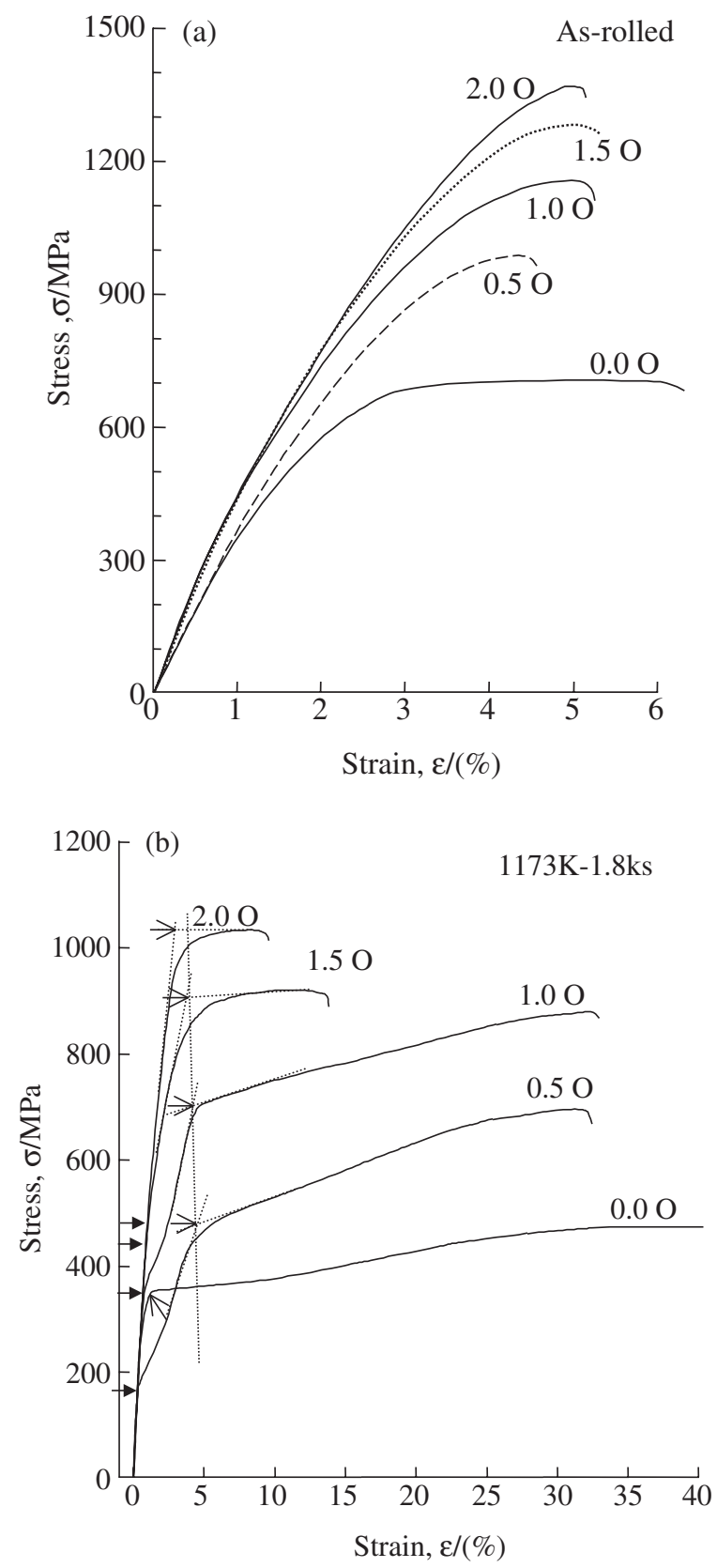

Fig. 1 stress-strain curves obtained at room temperature for Ti-22 at $\% \mathrm{Nb}-$ (0-2.0) at\%O alloys; (a) as-rolled specimens and (b) after solution treatment at $1173 \mathrm{~K}$ for $1.8 \mathrm{ks}$.

\section{Results and Discussion}

Figure 1 shows strain-stress curves obtained by tensile tests at room temperature in $\mathrm{Ti}-22$ at $\% \mathrm{Nb}$ specimens with different oxygen contents: (a) as-rolled specimens and (b) specimens solution treated at $1173 \mathrm{~K}$ for $1.8 \mathrm{ks}$. The stressstrain curves of a binary $\mathrm{Ti}-22$ at $\% \mathrm{Nb}$ alloy are also shown in the figures for reference. Hereafter, $\mathrm{Ti}-22 \mathrm{at} \% \mathrm{Nb}-x \mathrm{at} \% \mathrm{O}$ alloy is abbreviated to $\mathrm{Ti}-22 \mathrm{Nb}-x \mathrm{O}$ alloy. As shown in Fig. 1(a), all alloys other than the Ti-22Nb alloy fractured after exhibiting only small plastic deformation. Fracture stress and Young's modulus of the as-rolled specimens increase with increasing oxygen content. The fracture stress of $1.37 \mathrm{GPa}$ was obtained in the case of $\mathrm{Ti}-22 \mathrm{Nb}-2.0 \mathrm{O}$ alloy.
As shown in Fig. 1(b), the fracture stress of solution treated specimens also increases with increasing oxygen content. The fracture stress of $1.04 \mathrm{GPa}$ was obtained in the solution treated $\mathrm{Ti}-22 \mathrm{Nb}-2.0 \mathrm{O}$ alloy. This fracture stress is the highest one among solution-treated Ti-based $\beta$ type shape memory alloys which have been investigated to date. The Ti$22 \mathrm{Nb}-(0.5-2.0) \mathrm{O}$ alloys exhibit two-stage yield as shown by arrows, the first stage yielding being clearly confirmed in magnified stress-strain curves in Fig. 5. The first yielding seems to correspond to the deformation of the martensite variants or the stress-induced martensitic transformation. Therefore, it is supposed that the Ti-22Nb-(0.5-2.0)O alloys exhibit shape memory effect or superelasitic behavior at room temperature. Both yield stresses of the first and second stages for each alloy increase with increasing oxygen content. It is interesting to note that the strain at which the second stage yielding appears as indicated by white-headed arrows decreases with increasing oxygen content except the sample without oxygen.

The fracture stress and fracture strain were evaluated using the stress-strain curves of the $\mathrm{Ti}-22 \mathrm{Nb}-(0-2.0) \mathrm{O}$ alloys in Fig. 1, and they are plotted as functions of oxygen content as shown in Fig. 2. The fracture stresses of both as-rolled and solution-treated specimens increase with increasing oxygen content: they increase by $335 \mathrm{MPa}$ and $285 \mathrm{MPa}$, respectively, per 1 at\% increase of oxygen content. This is due to solidsolution hardening by oxygen. On the other hand, the fracture strain of the solution treated specimen decreases with increasing oxygen content from $40 \%$ for the $\mathrm{Ti}-22 \mathrm{Nb}$ alloy to $9.5 \%$ for the $\mathrm{Ti}-22 \mathrm{Nb}-2.0 \mathrm{O}$ alloy. However, the fracture strain of the as-rolled specimen does not depend on oxygen content.

In order to identify constituent phases at each heattreatment temperature, X-ray diffraction measurement was carried out at room temperature using the specimens which are as-rolled and heat-treated at temperatures between $773 \mathrm{~K}$ and $1173 \mathrm{~K}$ followed by quenching into water. Figure 3 shows $\mathrm{X}$-ray diffraction patterns of the $\mathrm{Ti}-22 \mathrm{Nb}-1.0 \mathrm{O}$ alloy.

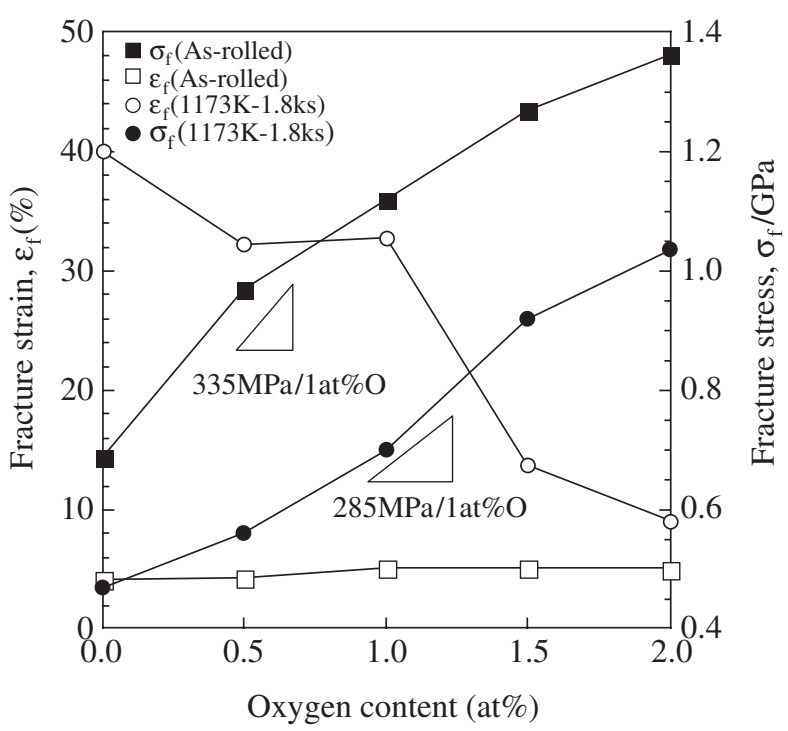

Fig. 2 Effect of oxygen content on fracture stress and strain in the Ti22 at $\% \mathrm{Nb}-(0-2.0)$ at $\% \mathrm{O}$ alloys subjected to solution treatment at $1173 \mathrm{~K}$ for $1.8 \mathrm{ks}$. 


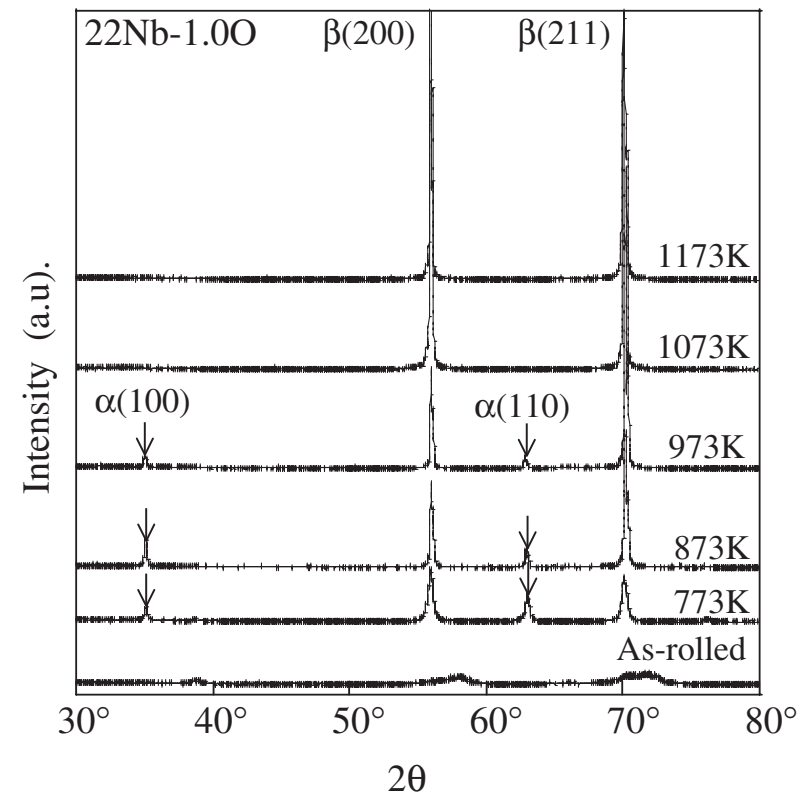

Fig. 3 XRD profiles obtained at room temperature in the as-rolled and annealed $\mathrm{Ti}-22 \mathrm{at} \% \mathrm{Nb}-1.0 \mathrm{atO}$ alloys.

The peaks corresponding to $\alpha^{\prime \prime}$ phase (orthorhombic martensite phase) can not be observed and there exist the peaks corresponding to $\beta$ phase in all specimens. This indicates that $M_{\mathrm{s}}$ (martensitic transformation start temperature) of these specimens are below room temperature. The peaks corresponding to $\alpha$ phase (hcp phase) are observed in the specimens heat-treated at temperatures between $773 \mathrm{~K}$ and $973 \mathrm{~K}$, however, they are not observed in the specimens heattreated at or above $1073 \mathrm{~K}$. This implies that the $\alpha / \beta$ transus temperature of the Ti-22Nb-1.O alloy locates between $973 \mathrm{~K}$ and $1073 \mathrm{~K}$.

Figure 4 shows the relationship between the $\alpha / \beta$ transus temperature and oxygen content in the $\mathrm{Ti}-22 \mathrm{Nb}-(0.5-2.0) \mathrm{O}$ alloys. The $\alpha / \beta$ transus temperatures of these alloys were also estimated using the same method described in Fig. 3. For reference, the $\alpha / \beta$ transus temperatures of Ti-O alloys and the $\mathrm{Ti}-22 \mathrm{Nb}$ binary alloy were estimated from $\mathrm{Ti}-\mathrm{O}$ and $\mathrm{Ti}-$ $\mathrm{Nb}$ equilibrium phase diagrams, and they are plotted together with the data measured in the present work in Fig. 4. Addition of 1 at $\%$ oxygen to pure Ti increased the $\alpha / \beta$ transus temperature by $88 \mathrm{~K}$, revealing that oxygen is an $\alpha$ stabilizer. The $\alpha / \beta$ transus temperature of the Ti-22Nb- $(0-$ $2.0) \mathrm{O}$ alloys increases by $200 \mathrm{~K}$ with 1 at $\%$ increase of oxygen content. This implies that the effect of adding oxygen for increasing the $\alpha / \beta$ transus temperature is more effective in the ternary $\mathrm{Ti}-\mathrm{Nb}-\mathrm{O}$ system than in binary $\mathrm{Ti}-\mathrm{O}$ system. It is important to know the $\alpha / \beta$ transus temperature for each specimen in order to control the heat treatment condition which is effective for improving the shape memory characteristics using the precipitation hardening due to $\alpha$ phase.

In order to investigate shape memory and superelastic behavior, tensile tests were carried out at room temperature. Figure 5 shows a series of stress-strain curves for the Ti$22 \mathrm{Nb}-(0-2.0) \mathrm{O}$ alloys subjected to heat treatment at $1173 \mathrm{~K}$. Tensile stress was applied until reaching $2.5 \%$ strain, then the stress was removed. After unloading, three specimens, (a)-

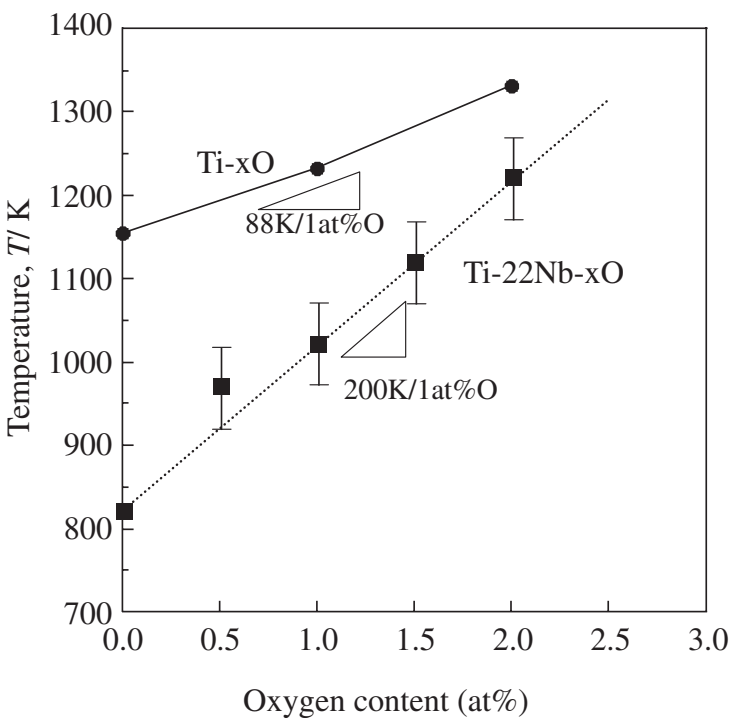

Fig. 4 Effect of addition of oxygen on $\alpha / \beta$ transus temperature estimated from XRD measurement at room temperature in the Ti-22 at $\% \mathrm{Nb}-(0-$ 2.0) at $\% \mathrm{O}$ alloys subjected to solution treatment at $1173 \mathrm{~K}$ for $1.8 \mathrm{ks}$.
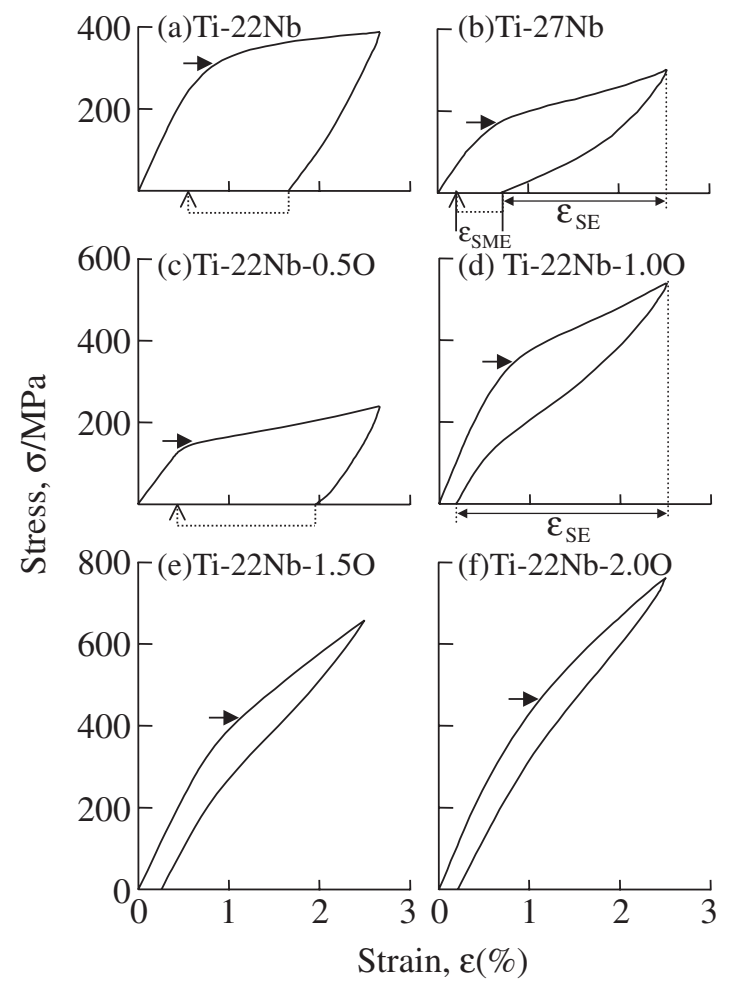

Fig. 5 stress-strain curves at room temperature in the $\mathrm{Ti}-22 \mathrm{Nb}-(0-2.0) \mathrm{O}$ and $\mathrm{Ti}-27 \mathrm{Nb}$ alloys subjected to solution treatment at $1173 \mathrm{~K}$ for $1.8 \mathrm{ks}$.

(c), which do not exhibit superelasitc recovery were heated above martensitic transformation finish temperature $\left(A_{\mathrm{f}}\right)$. Dashed arrows indicate shape recovery due to the reverse martensitic transformation by heating after unloading. Blackheaded arrows indicate the yield stresses. The stress-strain curve for a solution treated $\mathrm{Ti}-27 \mathrm{Nb}$ alloy is also shown in this figure for comparison. The shape memory effect and superelastic behavior are observed in the $\mathrm{Ti}-22 \mathrm{Nb}-(0-0.5) \mathrm{O}$ 
alloys and $\mathrm{Ti}-22 \mathrm{Nb}-(1.0-2.0) \mathrm{O}$ alloys, respectively. Therefore, the yield stresses indicated by the white-headed arrows for the $\mathrm{Ti}-22 \mathrm{Nb}-(0-0.5) \mathrm{O}$ alloys are those for the rearrangement of martensite variants, and those for the Ti-22Nb- 1.0 2.0)O alloys correspond to the stresses for inducing martensites. The yielding stress decreases with increasing oxygen content down to the minimum in the $\mathrm{Ti}-22 \mathrm{Nb}-0.5 \mathrm{O}$ alloy and increases with further increasing oxygen content. This means that the $M_{\mathrm{s}}$ decreases with increasing oxygen and the $M_{\mathrm{S}}$ of $\mathrm{Ti}-22 \mathrm{Nb}-0.5 \mathrm{O}$ alloy is closest to room temperature. On the other hand, the $\mathrm{Ti}-27 \mathrm{Nb}$ alloy exhibits incomplete superelasitc behavior, i.e., the strain is partly recovered superelastically upon unloading $\left(\varepsilon_{\mathrm{SE}}=1.8 \%\right)$, while remaining strain is partly recovered by the shape memory effect upon heating $\left(\varepsilon_{\mathrm{SME}}=0.5 \%\right)$. The strain recovered superelastically in the $\mathrm{Ti}-27 \mathrm{Nb}$ alloy is largest among the $\mathrm{Ti}-\mathrm{Nb}$ binary alloys. ${ }^{13)}$ Comparing with the $\mathrm{Ti}-27 \mathrm{Nb}$ alloy, the $\mathrm{Ti}-$ $22 \mathrm{Nb}-1.0 \mathrm{O}$ alloy shows better superelastic behavior, because the strain is almost recovered superelastically with a plastic strain of only $0.2 \%$. This implies that addition of oxygen to the $\mathrm{Ti}-\mathrm{Nb}$ alloy is effective in improving the superelastic behavior. It is also interesting to note that the Ti-22Nb-2.0O alloy shows stable superelastic behavior with a plastic strain of only $0.2 \%$ even after deformation reaching $800 \mathrm{MPa}$ stress and $2.5 \%$ strain.

In order to develop biomedical shape memory alloys, it is also important to control transformation temperatures by adding the third element, because the martensitic transformation temperatures should be adjusted nearly to human body temperature. For the purpose of investigating the effect of oxygen content on $M_{\mathrm{S}}$, the $M_{\mathrm{S}}$ temperatures of all the specimens, which were subjected to heat-treatment at $1173 \mathrm{~K}$, were measured by the following ways. The specimens were deformed to the strain of $2.5 \%$ at various temperatures, followed by unloading. After unloading they were heated to $500 \mathrm{~K}$ to observe shape recovery. Figure 6 shows a series of stress-strain curves obtained at various

\section{Ti-22Nb-0.5O, 1173K-1.8ks}

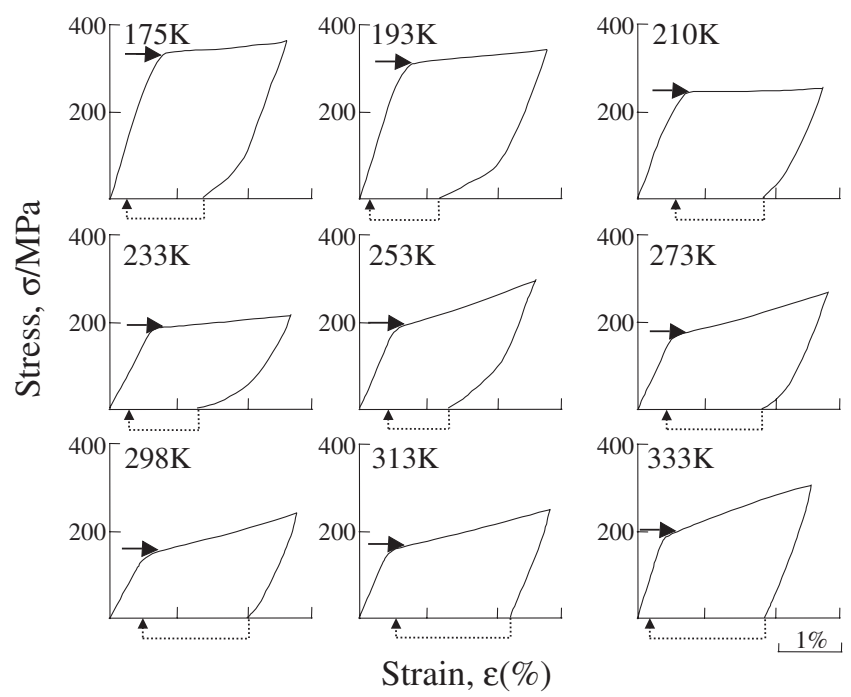

Fig. 6 stress-strain curves obtained at various temperatures for $\mathrm{Ti}-$ 22 at $\% \mathrm{Nb}-0.5$ at\%O alloys subjected to solution treatment at $1173 \mathrm{~K}$ for $1.8 \mathrm{ks}$.

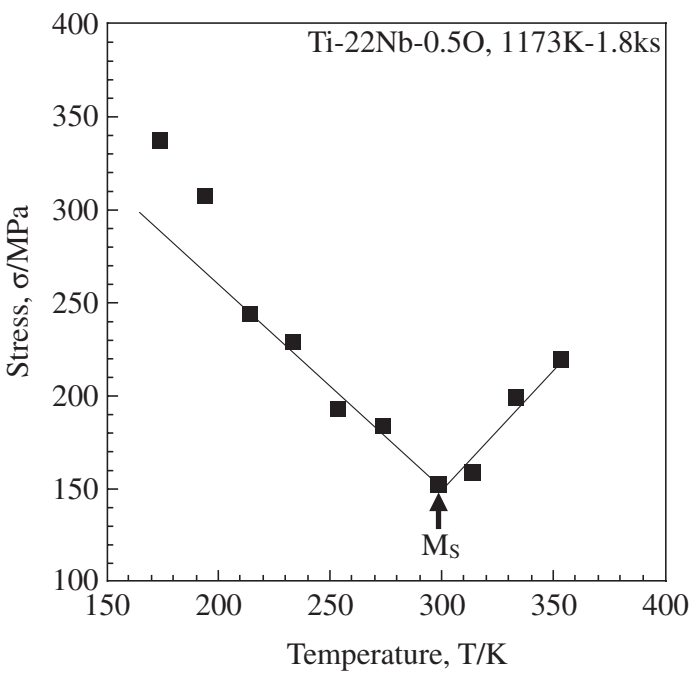

Fig. 7 Temperature dependence of critical yielding stress for Ti22 at $\% \mathrm{Nb}-0.5$ at\% $\mathrm{O}$ alloys subjected to solution treatment at $1173 \mathrm{~K}$ for $1.8 \mathrm{ks}$.

temperatures for the $\mathrm{Ti}-22 \mathrm{Nb}-0.5 \mathrm{O}$ alloy. The shape memory effect was observed for all specimens. The residual strain after unloading is partly recovered by heating to $500 \mathrm{~K}$ as indicated by dashed arrows. The superelasitic behavior can not be observed for the specimens deformed at any temperature. This is because the reverse martensitic transformation finish temperature $\left(A_{\mathrm{f}}\right)$ is above all the test temperatures used in this study. The yielding stresses indicated by the blackheaded arrows for the stress-strain curves were plotted against test temperature in Fig. 7. This yield stress for the Ti$22 \mathrm{Nb}-0.5 \mathrm{O}$ decreases with increasing test temperature to the minimum at $298 \mathrm{~K}$, and increases with further increasing test temperature. In general, the temperature exhibiting the minimum yield stress is considered to be $M_{\mathrm{s}}$. Thus, the $M_{\mathrm{s}}$ of the Ti-22Nb-0.5O alloy is determined to be $298 \mathrm{~K}$. The $M_{\mathrm{s}}$ temperatures for all alloys were determined by the same method and they were plotted in Fig. 8, revealing the oxygen content dependence of $M_{\mathrm{s}}$ in the Ti-22Nb-(0-2.0)O alloys. The $M_{\mathrm{s}}$ decreases by $160 \mathrm{~K}$ with 1 at $\%$ increase of oxygen content.

Figure 9 shows stress-strain curves of the Ti-22Nb-0.5O alloy heat-treated at $1173 \mathrm{~K}$. Each stress-strain curve was obtained at room temperature by a loading and unloading cycle and strain recovery was measured as shown by an arrow by the following heating up to $A_{\mathrm{f}}$. The similar measurement was repeated by increasing the maximum strain by $0.5 \%$ starting from 1.5 to $6 \%$ using the same sample. In order to characterize the shape memory behavior of the sample, two types of strains are defined as follows; (1) a total recovered strain $\varepsilon_{\text {Tot }}$ consisting of strains recovered upon unloading and upon following heating, and (2) a permanently remained strain $\varepsilon_{\mathrm{P}}$.

Figure 10 shows the stress dependence of $\varepsilon_{\text {Tot }}$ and $\varepsilon_{\mathrm{P}}$ measured in Fig. 9. As shown in Fig. 10, the $\varepsilon_{\text {Tot }}$ increases with increasing applied stress up to the maximum of $4 \%$, and then decreases with further increasing applied stress. On the other hand, the $\varepsilon_{\mathrm{P}}$ monotonously increases with increasing applied stress. Generally speaking, the stability of shape 


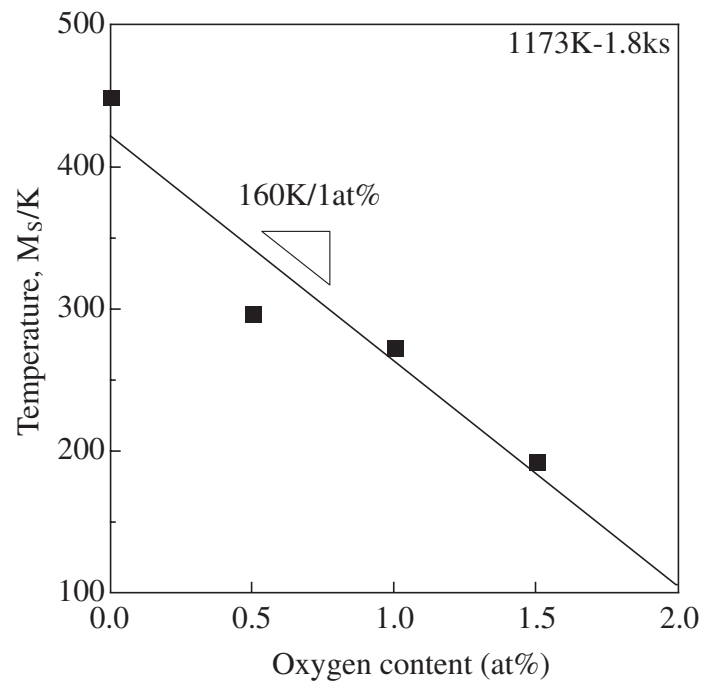

Fig. 8 Oxygen content dependence of martentsitic transformation start temperature $\left(M_{\mathrm{s}}\right)$ estimated by strain-stress curves for Ti-22 at $\% \mathrm{Nb}-(0.5-$ 2.0) at $\% \mathrm{O}$ alloys subjected to solution treatment at $1173 \mathrm{~K}$ for $1.8 \mathrm{ks}$.

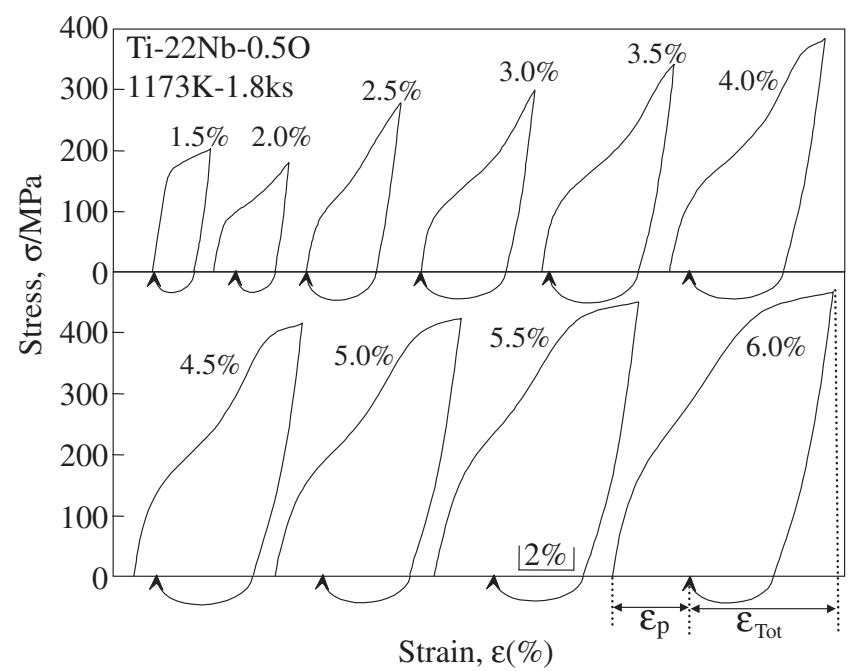

Fig. 9 Stress-strain curves obtained by cyclic loading-unloading tensile test for $\mathrm{Ti}-22$ at $\% \mathrm{Nb}-0.5$ at $\% \mathrm{O}$ alloys subjected to solution treatment at $1173 \mathrm{~K}$ for $1.8 \mathrm{ks}$.

memory behavior can be evaluated by the critical stress $\left(\sigma_{\mathrm{S}}\right)$ for slip and the maximum recovery strain $\left(\varepsilon_{\mathrm{Tot}}^{\max }\right)$. The $\sigma_{\mathrm{s}}$ indicated by a white-headed arrow is defined in this study as the stress where $0.5 \%$ plastic strain is induced, while the $\varepsilon_{\text {Tot }}^{\max }$ indicated by a black-headed arrow is the maximum total recovery strain as shown in Fig. 10. The $\sigma_{\mathrm{S}}$ is estimated to be about $380 \mathrm{MPa}$, while the $\varepsilon_{\text {Tot }}^{\max }$ to be $4 \%$ in the case of the Ti$22 \mathrm{Nb}-0.5 \mathrm{O}$ alloy heat-treated at $1173 \mathrm{~K}$. The same measurement was carried out for all the alloys.

All the $\sigma_{\mathrm{S}}$ and the $\varepsilon_{\text {Tot }}^{\max }$ estimated for the Ti-22Nb- $(0.5-$ 2.0)O alloys heat-treated at 1173 are plotted against oxygen content in Fig. 11. The $\sigma_{\mathrm{S}}$ increases up to $890 \mathrm{MPa}$ with increasing oxygen content. This phenomenon can be attributed to the solution hardening effect of oxygen atoms. The $\sigma_{\mathrm{S}}$ of $890 \mathrm{MPa}$ is the highest value among those of Ti-based

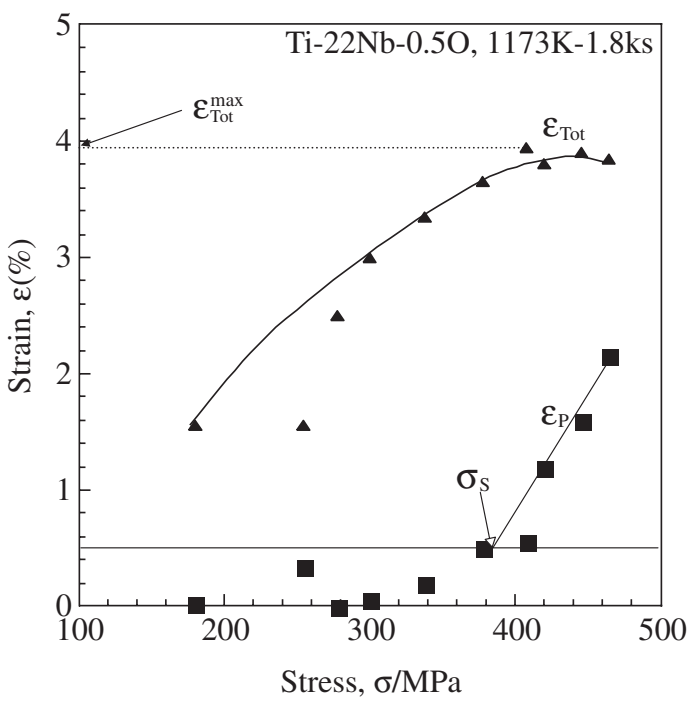

Fig. 10 Stress dependence of recovery and plastic strain for $\mathrm{Ti}-22 \mathrm{at} \% \mathrm{Nb}-$ 0.5 at\% $\mathrm{O}$ alloys subjected to solution treatment at $1173 \mathrm{~K}$ for $1.8 \mathrm{ks}$.

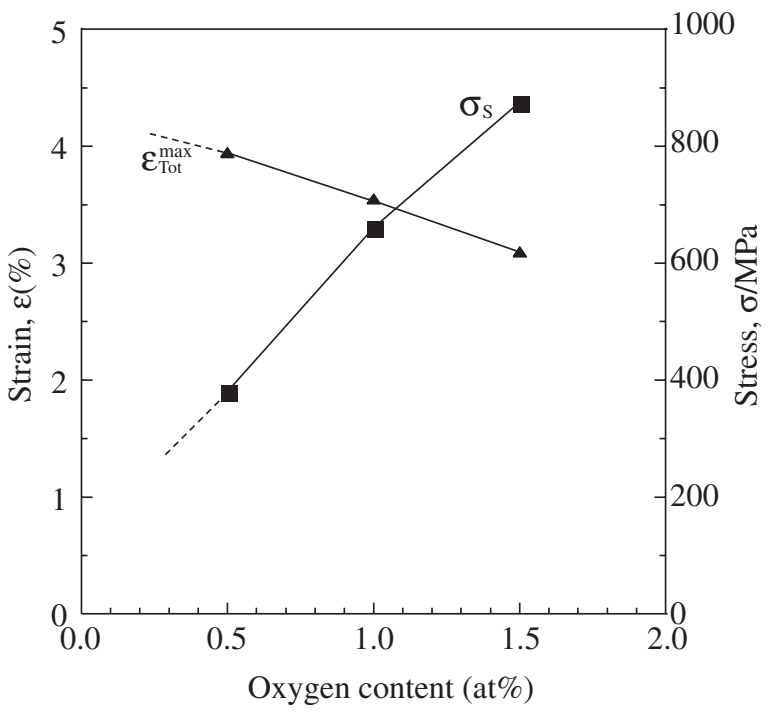

Fig. 11 Oxygen content dependence of maximum recovery strain and the critical stress for slip for $\mathrm{Ti}-22$ at $\% \mathrm{Nb}-(0-2.0)$ at $\% \mathrm{O}$ alloys subjected to solution treatment at $1173 \mathrm{~K}$ for $1.8 \mathrm{ks}$.

ternary biomedical shape memory alloys which have been investigated to date. On the other hand, the $\varepsilon_{\mathrm{Tot}}^{\max }$ decreases from about $4 \%$ at oxygen content of 0.5 at $\%$ to about $3 \%$ at oxygen content of 1.5 at $\%$ with increasing oxygen content. It is supposed that the strain $\left(\varepsilon_{\mathrm{Y} 2 \mathrm{nd}}\right)$ at which the second stage yielding appears, i.e., the permanent stain is first introduced, decreases with increasing oxygen content, as shown in Fig. 1(b). The strain induced after the second stage yielding relates to the plastic strain, $\varepsilon_{\mathrm{P}}$, while the total recovery strain $\left(\varepsilon_{\text {Tot }}\right)$ due to transformation relates to the $\varepsilon_{\mathrm{Y} 2 \text { nd }}$. Therefore, the $\varepsilon_{\text {Tot }}^{\max }$ decreases with decreasing $\varepsilon_{\mathrm{Y} 2 \text { nd }}$. In conclusion, adding oxygen to the binary $\mathrm{Ti}-\mathrm{Nb}$ alloy is an effective method to improve mechanical and shape memory properties, such as the strength, the critical stress for slip and the maximum recovery strain. 


\section{Conclusions}

In order to develop Ni-free Ti-based biomedical shape memory alloys, the $\mathrm{Ti}-22 \mathrm{at} \% \mathrm{Nb}-(0.5-2.0)$ at $\% \mathrm{O}$ alloys were investigated to clarify the effect of addition of oxygen to the $\mathrm{Ti}-\mathrm{Nb}$ binary alloy on shape memory behavior and mechanical properties. The obtained results are as follows;

(1) Adding oxygen to the $\mathrm{Ti}-\mathrm{Nb}$ binary alloy causes increasing fracture stress and decreasing fracture strain because of solid-solution hardening effect. The maximum fracture stress of $1.37 \mathrm{GPa}$ is obtained in the case of an as-rolled $\mathrm{Ti}-22 \mathrm{at} \% \mathrm{Nb}-2.0$ at $\% \mathrm{O}$ alloy.

(2) The $\alpha / \beta$ transus temperature in the Ti-22 at $\% \mathrm{Nb}-(0$ 2.0) at $\% \mathrm{O}$ alloys increases by $200 \mathrm{~K}$ with 1 at $\%$ increase of oxygen. Comparing to the Ti-O binary system, the effect of adding oxygen for increasing the $\alpha / \beta$ transus temperature is more effective in the ternary $\mathrm{Ti}-\mathrm{Nb}-\mathrm{O}$ system.

(3) The martentsitic transformation start temperature $\left(M_{\mathrm{S}}\right)$ decreases by $160 \mathrm{~K}$ with $1 \mathrm{at} \%$ increase of oxygen content. The shape memory effect and superelasitc behavior are observed in the $\mathrm{Ti}-22 \mathrm{at} \% \mathrm{Nb}-(0-0.5)$ at $\% \mathrm{O}$ alloys and the $\mathrm{Ti}-22 \mathrm{at} \% \mathrm{Nb}-(1.0-1.5)$ at $\% \mathrm{O}$ alloys, respectively.

(4) The critical stress for slip increases up to $890 \mathrm{MPa}$ in a $\mathrm{Ti}-22 \mathrm{at} \% \mathrm{Nb}-1.5$ at $\% \mathrm{O}$ alloy with increasing oxygen content. The maximum total recovery strain decreases from $4 \%$ in a Ti-22 at $\% \mathrm{Nb}-0.5$ at $\% \mathrm{O}$ alloy to $3 \%$ in a $\mathrm{Ti}-22$ at $\% \mathrm{Nb}-1.5 \mathrm{at} \% \mathrm{O}$ alloy with increasing oxygen content. It is confirmed that adding oxygen to the $\mathrm{Ti}-\mathrm{Nb}$ binary alloys causes increasing in the critical stress for slip due to solution hardening effect.

\section{Acknowledgments}

This work was partially supported by the 21 Century Center of Excellence Program and the Grants-in-Aid for Fundamental Scientific Research (Kiban A (1999-2001), Kiban A (2002-2004) from the Ministry of Education, Culture, Sports, Science and Technology, Japan.

\section{REFERENCES}

1) S. Shabalovskaya: Proc. First Inter. Conf. Shape Memory and Superelastic Technologies, (1994) 209.

2) T. W. Deurig, J. Albrecht, D. Richter and P. Fischer: Acta. Metall. 30 (1982) 2161-2172.

3) W. F. Ho, C. P. Ju and J. H. Chern Lin: Biomaterials 20 (1999) 21152122.

4) T. Grosdidier and M. J. Philippe: Mater. Sci. Eng. A 291 (2000) 218223.

5) H. Hosoda, N. Hosoda and S. Miyazaki: Trans. MRS-J 26 (2001) 243246.

6) T. Maeshima and M. Nishida: Mater. Trans. 45 (2004) 1096-1100.

7) T. Maeshima and M. Nishida: Mater. Trans. 45 (2004) 1101-1105.

8) H. Y. Kim, Y. Ohmatsu, J. I. Kim, H. Hosoda and S. Miyazaki: Mater. Trans. 45 (2004) 1090-1095.

9) M. Yonezawa, H. Y. Kim, J. I. Kim, H. Hosoda and S. Miyazaki: unpublished work.

10) C. Baker: Mater Sci. J. 5 (1971) 92-100.

11) K. Nitta, S. Watanabe, N. Masahashi, H. Hosoda and S. Hanada: Structural Biomaterials for the 21st Century, (TMS, 2001) 25-34.

12) H. Hosoda, Y. Fukui, T. Inamura, K. Wakashima, S. Miyazaki and K. Inoue: Mater. Sci. Forum 425-432 (2003) 3121.

13) H. Y. Kim, S. Hashimoto, J. I. Kim, H. Hosoda and S. Miyazaki: Mater. Trans. 45 (2004) 2443-2448.

14) J. I. Kim, H. Y. Kim, Y. Ohmatsu, H. Hosoda and S. Miyazaki: Collected Abstracts of the 2003 Fall Meeting of the Japan Inst. Metals, p. 149.

15) N. Oshika, S. Hashimoto, J. I. Kim, H. Y. Kim, Y. Ohmatsu, H. Hosoda and S. Miyazaki: Collected Abstracts of the 2003 Fall Meeting of the Japan Inst. Metals, p. 149.

16) N. Oshika, J. I. Kim, H. Y. Kim, Y. Ohmatsu, H. Hosoda and S. Miyazaki: Collected Abstracts of the 2004 Fall Meeting of the Japan Inst. Metals, p. 330.

17) H. Y. Kim, S. Hashimoto, J. I. Kim, H. Hosoda and S. Miyazaki: Collected Abstracts of the 2004 Spring Meeting of the Japan Inst. Metals, p. 327.

18) Y. Ohmatsu, J. I. Kim, H. Hosoda and S. Miyazaki: Collected Abstracts of the 2003 Spring Meeting of the Japan Inst. Metals, p. 144.

19) N. Oshika, J. I. Kim, H. Y. Kim, H. Hosoda and S. Miyazaki: unpublished data.

20) S. Annaka, T. Furuhara and M. Maki: Collected Abstracts of the 2004 Fall Meeting of the Japan Inst. Metals, p. 333.

21) T. Miyazaki, H. Matsumoto, S. Watanabe, S. Hanada and T. Saburi: Collected Abstracts of the 2004 Fall Meeting of the Japan Inst. Metals, p. 466.

22) T. Saito et al.: Science 300 (2003) 464-467. 